Revista Energia na Agricultura

ISSN 1808-8759

\title{
EFICIÊNCIA E ENERGÉTICA DE SISTEMAS DE PRODUÇÃO DE MAMONA NO ESTADO DE MINAS GERAIS

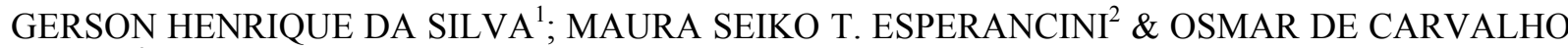 BUENO $^{3}$
}

RESUMO: Este estudo teve por objetivo determinar a eficiência econômica e energética da cultura da mamona nas regiões da Zona da Mata e Sul de Minas Gerais. Através do método de simulação de Monte Carlo, verificaram-se as probabilidades de ocorrência dos índices de eficiência econômica e cultural. Com relação aos sistemas de produção da mamona em Minas Gerais na safra 2005/2006, constatou-se que as variáveis preço e produtividade foram as mais sensíveis para os produtores da Zona da Mata, enquanto que no Sul de Minas foi a produtividade. Verificou-se que a probabilidade do índice de eficiência econômica ser menor que um foi de 43,26\% para os produtores da região da Zona da Mata e 39,57\% para os do Sul de Minas. O preço médio recebido cobriu os custos médios de produção. Contudo, observou-se que os custos médios nestas regiões de Minas Gerais, estiveram acima do preço mínimo. Quanto a análise energética, os resultados mostraram que os sistemas das regiões estudadas em Minas Gerais, apresentaram índices de eficiência cultural média de 8,26. Concluiu-se que, mesmo que do ponto de vista energético o resultado tenha sido favorável, sob a ótica da sustentabilidade econômica há necessidade de uma política mais efetiva de apoio à mamona, já que as expectativas dos produtores com o PNPB não se confirmaram.

Palavras-chave: Análise energética, mamona, agroenergia, agricultura familiar.

\footnotetext{
${ }^{1}$ Doutor em Energia na Agricultura - UNESP - Campus de Botucatu. End: Rua João Dias Cordeiro, 17 - Vila Pinheiro Machado Cep: 18609-450 Botucatu. Fone: 14-38824844 - email: ghsilva@unioeste.br

${ }^{2}$ Prof a Livre-Docente Faculdade de Ciências Agronômicas - UNESP - Campus de Botucatu. Depto Economia Rural. End: Rua José Barbosa de Barros, 1780. Cep: 18603-970. Fone: 14-3811 7164 - email: maura@,fca.unesp.br

${ }^{3}$ Prof. Dr. Faculdade de Ciências Agronômicas - UNESP - Campus de Botucatu. Depto Economia Rural. End: Rua José Barbosa de Barros, 1780. Cep: 18603-970. Fone: 14-3811 7164 - email: osmar@,fca.unesp.br
} 


\section{ECONOMICAL AND ENERGETIC EFFICIENCY OF CASTOR BEAN PROFICIENCY SYS- TEMS IN THE STATE OF MINAS GERAIS}

SUMMARY: The objective of this study is to determine the economical and energetic efficiency of the castor bean culture in "Zona da Mata" and South of Minas Gerais. Through the method of simulation "Monte Carlo", we verified the probabilities of occurrence of the economical, cultural and energetic efficiency indexes. In relation to the production systems of castor bean in Minas Gerais in the season 2005/2006, we established that the variables price and productivity were the most noticeable for the producers from "Zona da Mata", while in the South of Minas it was productivity. We verified that the probability of the economical efficiency index to be lower than one was 43,26\% for the producers from "Zona da Mata" and 39,57\% for the ones from the South of Minas. The medium price received covered the medium costs of production. However, we observed that the medium costs in these regions of Minas Gerais, were over the minimum price. Regarding the energetic analysis, the results showed that the systems in the regions studied in Minas Gerasi, presented average of cultural efficiency indexes of 8,26 and 18,89. We concluded that despite the result being favorable from the energetic point of view, from the economical sustainability point of view there is the need of a more effective support policy for the castor bean, taking into consideration that the expectations of the producers with PNPB were not confirmed.

Keywords: Energetic analysis, castor bean, agroenergy, family agriculture.

\section{INTRODUÇÃO}

A crescente preocupação com o meio ambiente e, especificamente, com as mudanças climáticas globais, coloca em xeque a própria sustentabilidade do atual padrão de consumo energético. O crescimento contínuo da demanda energética, as limitações naturais de extração de combustíveis fósseis, especialmente o petróleo, impõem a necessidade de diversificar a atual matriz energética, com prioridade para fontes renováveis e limpas. As fontes alternativas ao petróleo causam impactos substancialmente menores e podem reduzir a emissão de toneladas de gás carbônico na atmosfera

No Brasil, de acordo com o Balanço Energético Nacional- BEN, em termos agregados, a Oferta Interna de Energia - OIE, atingiu o montante de 218,7 milhões de toneladas equivalentes de petróleo 
$\left(\mathrm{TEP}^{4}\right)$, significando um crescimento de 2,3\% em relação a 2004. Verificou-se, ainda, que mais de $40 \%$ da matriz energética brasileira é renovável, enquanto a média mundial não chega a $14 \%$. No entanto, $90 \%$ da energia elétrica do país é gerada em grandes usinas hidrelétricas, o que provoca impactos ambientais, como o alagamento de grandes áreas, levando a perda da biodiversidade local, além dos problemas sociais (BRASIL, 2005).

Com a implementação do Programa Nacional de Produção e Uso de Biodiesel (PNPB), por meio da lei 11.097 de janeiro de 2005, procurou-se introduzir o biodiesel na matriz energética brasileira, fixando percentuais de mistura do combustível vegetal ao fóssil.

A adoção do Programa aponta para a valorização dos aspectos ambientais, da sustentabilidade dos sistemas energéticos e da inclusão social, capitaneado pela produção deste combustível renovável. Com a lei, o biodiesel necessário para a mistura, recebe incentivos para ser produzido preferencialmente a partir de matérias-primas produzidas por meio da agricultura familiar. Neste aspecto, a mamona (Ricinus communis L.), por ser uma espécie produzida principalmente por pequenos produtores, é uma das que são previstas para o uso na produção de biodiesel.

Segundo Savy Filho (2005), a produção da mamona no Brasil, que já ocupou a primeira posição mundial no período 1978-1982, concentra-se, de modo geral, em pequenas propriedades, classificadas como agricultura familiar. Neste segmento o nível de tecnologia utilizado é baixo, resultando na produtividade média nacional de $500 \mathrm{~kg} \cdot \mathrm{ha}^{-1}$.

A produtividade da cultura em Minas Gerais, entre os anos de 2003 e 2005, mostrou-se superior à do principal produtor nacional, a Bahia. No período, ocorreu um crescimento significativo da produção de mamona de $212,33 \%$, reflexo das expectativas dos produtores em relação ao programa de incentivo à produção de matéria-prima de origem familiar para a produção de biodiesel.

Além dos aspectos sociais relacionados à ocupação de mão-de-obra na agricultura, considera-se a importância crescente que sistemas de produção agrícolas mais sustentáveis vêm adquirindo frente aos elevados custos de energia e de produção. Assim, torna-se importante analisar a eficiência energética e econômica como mais um indicativo da sustentabilidade ambiental, particularmente, pelo uso de fluxos de energia não renovável, e a sustentabilidade econômica, condição para a permanência dos produtores agrícolas na atividade.

Diante disso, o objetivo deste estudo foi determinar, do ponto de vista econômico e energético, a eficiência da cultura da mamona. Esta cultura foi escolhida por sua importância econômica e social, na agricultura familiar e pela geração de renda e ocupação de mão-de-obra.

\footnotetext{
${ }^{4}$ Petróleo de referência $=10000$ kcal. $\mathrm{kg}^{-1}$ e utilização de Poderes Caloríficos Inferiores - PCI (critério aderente com a IEA e outros organismos internacionais)
} 


\section{MATERIAL E MÉTODOS}

Foram identificados dois tipos de sistemas produtivos da mamona: o sistema solteiro e o de combinação de culturas, especificamente os de culturas consorciadas ${ }^{5}$ e culturas intercaladas ${ }^{6}$. Analisou-se apenas o sistema solteiro, composto por uma amostra de 10 produtores distribuídos entre as duas regiões do estado de Minas Gerais. A partir do contato com as Secretarias de Agricultura dos municípios, foram obtidas informações preliminares sobre produtores de mamona. Com base nestes elementos, foi possível abordar o produtor, o que possibilitou identificar outros, aplicando-se, assim, a técnica "snowball sampling" na qual o investigador identifica um pequeno grupo de indivíduos que têm as características desejadas. Este serve de informante para identificarem outros com as mesmas características, assim sucessivamente até se obter a amostra (COHEN; MANION, 1989).

Os dados utilizados para a execução da pesquisa são referentes à safra 2005/2006, originários de fontes primárias obtidos com aplicação de questionários junto aos produtores de mamona e técnicos das regiões pesquisadas. Os dados secundários foram obtidos junto à Fundação Instituto Brasileiro de Geografia e Estatística, por meio da Produção Agrícola Municipal de Minas Gerais dos anos de 1990 a 2005 (IBGE, 2007); junto a Fundação Getúlio Vargas (FGV, 2008). Para obtenção de informações complementares, consultou-se outros órgãos, como os escritórios da EMATER de Divino, Fervedouro e Orizânia localizados na Zona da Mata e Varginha no Sul de Minas. Nestas mesmas fontes, foram coletadas informações que permitiram a localização dos produtores de mamona, dados de área colhida de mamona nas regiões, produção, variação na produtividade, preços pagos pelo produtor e mão-de-obra empregada nos sistemas produtivos analisados.

\subsection{Método}

Para as análises econômicas e energéticas da produção de mamona no estado de Minas Gerais, foi utilizada a técnica de simulação de Monte Carlo, através do software @Risk versão 4.5 (PALISADE CORPORATION, 2006).

Ao contrário da análise determinística, que utiliza valores únicos para a obtenção de um indicador do sistema (geralmente a média das variáveis críticas), a técnica de simulação de Monte Carlo permite incorporar as possibilidades de alterações destas variáveis, segundo as probabilidades de sua ocorrência, permitindo assim, captar a variabilidade de variáveis que influenciam o indicador, como preços, produtividade e custo.

$5 \quad$ Cultivo simultâneo de culturas anuais de espécies diferentes

6 Cultivo simultâneo de culturas perenes e temporárias 
A simulação de Monte Carlo requer um número maior de amostras para se aproximar da verdadeira distribuição, especialmente se esta é altamente assimétrica ou tem alguns resultados com baixa probabilidade.

Este método consiste das seguintes etapas:

1) Seleção e identificação das distribuições de probabilidades das variáveis em estudo.

a) Identificar a distribuição de probabilidade adequada utilizando-se o software Bestfit ${ }^{7}$

b) Estimar os parâmetros da distribuição encontrada

c) Validar o modelo estatístico pressuposto por meio de um teste de aderência, tais como o Quiquadrado, o teste de Kolmogorov-Smirnov ou o teste de Anderson-Darling. A escolha é realizada a partir do Bestfit, que lista as distribuições mais apropriadas a partir de cada tipo de teste. Esses testes de aderência mostram, com um certo nível de confiança, se o modelo está bem ajustado à realidade.

2) Seleção aleatória de um valor de cada variável em estudo, associada à probabilidade de sua ocorrência.

Após identificar as distribuições de probabilidades, escolhe-se, dentro de cada uma dessas, um valor para cada uma das variáveis selecionadas, que irão substituir os valores originais, permitindo estimar uma nova variável. O procedimento é feito simultaneamente em todas as variáveis simuladas e, após repetir um certo número de vezes, é permitido estabelecer uma distribuição de freqüência da variável em estudo.

3)Determinação do valor do indicador do sistema, conforme mostrado anteriormente.

4) Repetição das etapas 2 e 3, que podem ser feitas usando softwares específicos para este fim. Neste estudo foi utilizado o @Risk, que tem capacidade de geração de números aleatórios para 30 tipos de distribuição de probabilidade contínuas e discretas, permite a execução de até 10.000 interações, ou seleções aleatórias dos valores das variáveis simuladas e suas respectivas probabilidades a partir das distribuições de freqüências. Quanto maior o número de simulações executadas, maior a precisão dos resultados.

\subsubsection{Análise Econômica}

$\mathrm{Na}$ análise econômica do agroecossistema da mamona utilizou-se o índice de eficiência econômica determinado pela relação receita bruta / custo total da produção. A expressão utilizada para a determinação do indicador de eficiência econômica foi:

$7 \quad$ Recurso do @ Risk específico para essa finalidade 


$$
E c=(P \vee \cdot Q)(C a)^{-1}
$$

Onde:

$\mathrm{Ec}=$ eficiência econômica;

$\mathrm{P}_{\mathrm{V}}=$ distribuição de freqüência de preços $(\mathrm{R} \$ / \mathrm{kg})$;

$\mathrm{Q}=$ distribuição de freqüência da produtividade $(\mathrm{kg} / \mathrm{ha})$; e

$\mathrm{Ca}=$ distribuição de freqüência do custo operacional total por unidade de área ( $\mathrm{R} \$ / \mathrm{ha})$.

Quando o índice de eficiência econômica (Ec) apresentar:

Ec $>1 \rightarrow$ o sistema é lucrativo

Ec $<1 \rightarrow$ o sistema apresenta prejuízo

$\mathrm{Ec}=1 \rightarrow$ a receita é igual ao custo

Na determinação da receita total, foram utilizados os preços médios mensais recebidos pelos produtores de mamona no estado de Minas Gerais no período de janeiro de 2003 a dezembro de 2007. A série foi construída a partir do valor da produção da mamona para o estado (IBGE, 2008) e pela cotação mensal informada pela ABOISSA (2008).

A escolha do mês de julho de 2007 para correção dos preços, utilizando o IGP-DI da Fundação Getúlio Vargas (FGV, 2008), deve-se ao fato de que, neste período, já se colheu e comercializou mais de $70 \%$ da produção. Os preços apresentaram distribuição de probabilidade normal pelo teste do quiquadrado e para a produtividade, utilizou-se da distribuição triangular.

A estrutura de custo utilizada para representar os sistemas de produção da mamona foi a de custo total, desagregado em custos operacionais efetivos e totais. Nestes são consideradas as despesas diretas com insumos (sementes, fertilizantes, defensivos), serviços de operação (mão-de-obra e operação de máquinas) e de empreitas, e despesas indiretas, como depreciação de máquinas, encargos sociais, encargos financeiros. (MATSUNAGA et al., 1976). A soma das despesas diretas denomina-se Custo Operacional Efetivo (COE) e quando se soma a estas as despesas indiretas o resultado denomina-se Custo Operacional Total (COT).

O custo operacional total foi determinado a partir das matrizes de coeficientes técnicos elaborados por meio das informações levantadas em entrevistas de campo com os produtores das regiões e técnicos especializados e, no que se refere aos custos de máquinas agrícolas, utilizou-se a metodologia da ASAE (1999), que padroniza os custos de operação de máquinas agrícolas em combustível, lubrificantes e reparos e manutenção. 


\subsubsection{Análise Energética}

$\mathrm{O}$ indicador de eficiência energética, utilizado foi:

Eficiência Cultural $=($ Saídas Úteis $)(\text { Entradas Culturais })^{-1}$

O indicador de Eficiência Cultural, é um dos índices mais utilizados na literatura em análise energética de culturas agrícolas (BUENO, 2002). Considerou-se neste estudo, para a equação da eficiência energética, as saídas energéticas como o somatório de energia bruta dos produtos, e as entradas energéticas, como o total de energia biológica, fóssil e industrial.

Cada operação foi detalhada no sentido de identificar e especificar o(s) tipo(s) e quantidade(s) de máquina(s) e implemento(s) utilizado(s), bem como seu(s) respectivo(s) consumo(s) de combustível (eis), lubrificante(s) e graxa(s); o número de horas de cada operação; o material consumido; e a mão-de-obra envolvida, por unidade de área, quantificando-a e determinando, individualmente, o peso, altura, idade e gênero.

Os agricultores pesquisados em Minas Gerais utilizaram sementes da variedade Guarani, adotando-se o valor energético de $6631,60 \mathrm{kcal} \cdot \mathrm{kg}^{-1}$, correspondente a 27,77 MJ.kg ${ }^{-1}$ de semente de mamona, proposto Kort-Kamp et al. (2007)

Realizou-se a conversão das diversas unidades físicas encontradas em unidades energéticas, como também determinou-se o tempo de operação por unidade de área.

Adotou-se como unidade energética Joules e seus múltiplos (RISOUD, 1999), mais utilizado em estudos de eficiência energética, que equivale a 4,1868 calorias. Os resultados deste estudo são dados em Megajoules (MJ). Na determinação da energia aplicada pelos produtores nas operações que caracterizam o itinerário técnico, utilizou-se a metodologia apresentada por Bueno (2002), Romero (2005) e Almeida (2007), com as seguintes variáveis: mão-de-obra, sementes, combustível, óleo lubrificante, graxa, máquinas e implementos, corretivo de solo, fertilizantes químicos e defensivos

\section{RESULTADOS E DISCUSSÃO}

\subsection{A produção de mamona nas regiões da Zona da Mata e Sul de Minas}

A pesquisa identificou que as propriedades na região da Zona da Mata de Minas Gerais possuem área média de 24,6 hectares, cultivando 15,8 hectares. Da área utilizada com atividades agrícolas, 9,36 hectares foram destinados à produção de mamona. A produtividade média desta cultura situa-se no pata- 
mar de $1024 \mathrm{~kg} \cdot \mathrm{ha}^{-1}$. Este resultado supera em 38,19\% à média nacional que é de $741 \mathrm{~kg} \cdot \mathrm{ha}^{-1}$, mas está $24,43 \%$ abaixo da produtividade estadual que é de $1355 \mathrm{~kg} \mathrm{ha}^{-1}$ alcançada na safra 2005/2006. Constatou-se ainda, que a variedade Guarani é cultivada em todas as propriedades no sistema solteiro e atingiu na região, apenas $41 \%$ da produtividade esperada para esta variedade que é de $2500 \mathrm{~kg}$.ha ${ }^{-1}$. Na região, predomina o cultivo de café.

Em relação à posse da terra, $100 \%$ disseram ser proprietários e com renda média mensal de 6,2 salários mínimos, exclusiva da atividade agrícola. A mão-de-obra utilizada é predominantemente familiar na maior parte do processo de produção. Ocorrendo também a utilização, além de mão-de-obra familiar, mão-de-obra temporária.

Apesar da variedade Guarani permitir uma só colheita, na região, ocorreu a repetição da operação 2 vezes pela maioria e apenas um produtor realizou 3 colheitas, com média de 2,20 colheitas. A maior parte dos produtores cortou os cachos utilizando instrumentos como tesoura, alicate, facão e luvas para proteger as mãos, e os demais realizaram a quebra dos cachos e dos pés de mamona (Figura 1). O balaio foi o equipamento adotado por todos os produtores na colheita.

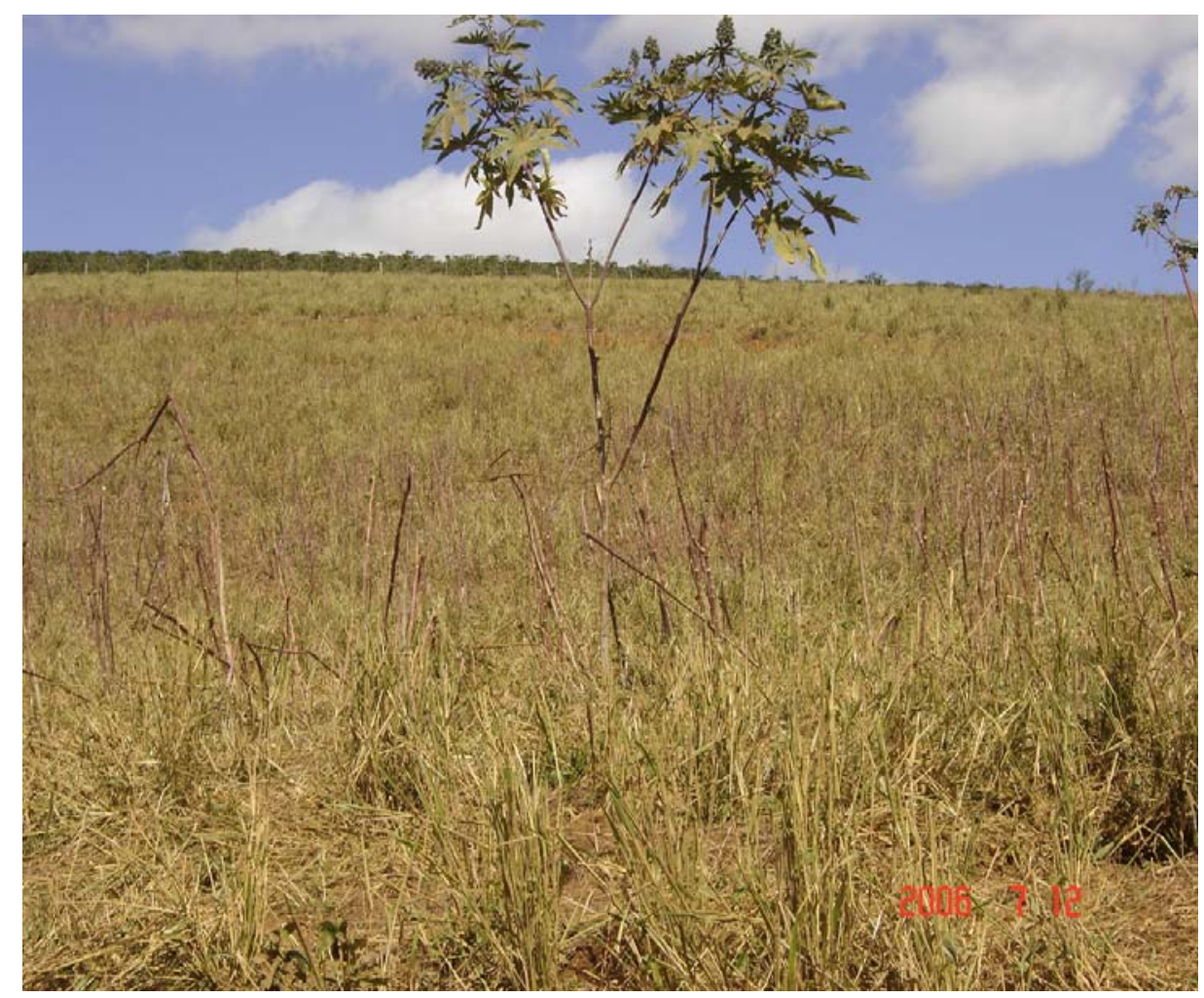

Figura 1 - Pós-colheita da mamona na região da Zona da Mata de Minas Gerais 
O PNPB é apontado pelos produtores como principal motivação para efetuarem o plantio da mamona. Relacionaram, ainda, dificuldades com a cultura do café, melhoria do solo, alternativa de renda e existência de mercado, na medida em que a empresa que incentivou o plantio da mamona, garantiu a compra da produção.

Na região Sul do Estado de Minas Gerais, foi possível identificar que as propriedades pesquisadas possuem área média de 29 hectares, cultivando 17,4 hectares. Da área utilizada com atividades agrícolas, 3,10 hectares foram destinados à produção de mamona. A produtividade média desta cultura situa-se no patamar de $1310 \mathrm{~kg} \cdot \mathrm{ha}^{-1}$. Este resultado supera em 76,79\% à média nacional que é de $741 \mathrm{~kg} \cdot \mathrm{ha}^{-1}$, está apenas 3,32\% abaixo da produtividade estadual que é de $1355 \mathrm{~kg} \cdot \mathrm{ha}^{-1}$ alcançada na safra 2005/2006. Constatou-se ainda, que a variedade Guarani é cultivada em todas as propriedades no sistema solteiro e atingiu na região, $52,40 \%$ da produtividade esperada para esta variedade que é de $2500 \mathrm{~kg} \cdot \mathrm{ha}^{-1}$. A região é tradicional produtora de café.

Todos os produtores disseram ser proprietários, com renda média mensal de 6 salários mínimos, exclusiva da atividade agrícola. Além da mão-de-obra familiar e mão-de-obra temporária, observou-se a existência, na maioria das propriedades, de dois empregados permanentes.

$\mathrm{Na}$ colheita foi utilizada uma tesoura de poda para o corte dos cachos. Realizou-se a operação duas vezes pela maioria e apenas um produtor colheu de uma só vez, contribuindo assim, para uma média 1,8 colheitas na região. Para recolher os cachos, o pano foi utilizado por todos os produtores na colheita.

Os incentivos da prefeitura, fornecendo semente, adubo, calcário e sulfato de amônia, foram apontados pelos produtores como principal motivação para efetuarem o plantio da mamona. Relacionaram, ainda, o Programa para a Produção de Biodiesel e a existência de mercado, já que a compra da produção foi garantida via contrato com a prefeitura.

\subsubsection{Eficiência econômica}

A partir da simulação, foram obtidos, pela relação receita/custos, os índices de Eficiência Econômica, para os sistemas de produção de mamona das regiões da Zona da Mata e Sul de Minas Gerais, conforme Tabela 1. 
Tabela 1 - Resultados estatísticos dos índices de eficiência econômica da produção de mamona nas regiões da Zona da Mata e Sul de Minas, safra 2005/2006.

\begin{tabular}{l|c|c}
\hline Indicadores & Zona da Mata & Sul de Minas \\
\hline Máximo & 3,34 & 3,99 \\
Mínimo & 0,14 & 0,12 \\
Média & 1,11 & 1,22 \\
Mediana & 1,06 & 1,09 \\
Moda & 1,45 & 1,03 \\
Desvio padrão & 0,35 & 0,54 \\
\hline Iterações & 10000 & 1000 \\
Erros & \\
\hline
\end{tabular}

Fonte: Resultados da pesquisa

Observa-se, para as duas regiões, que a média, a mediana e a moda apontam a probabilidade de ocorrência de um coeficiente de eficiência maior que um para a atividade de produção de mamona. $\mathrm{O}$ valor máximo do indicador de eficiência econômica na região da Zona da Mata foi de 3,34, inferior ao Sul de Minas que foi de 3,99 e, em ambas, o valor mínimo do coeficiente é inferior a um, o que deixa transparecer a possibilidade da produção de mamona mostrar prejuízo, pois o valor mínimo do índice foi de 0,14 na Zona da Mata e 0,12 no Sul de Minas, ou seja, para cada unidade de capital imobilizado na produção das regiões pesquisadas, resultou em um ganho mínimo de apenas 0,13 unidades monetárias na média .

O desvio padrão da região da Zona da Mata, apresentou uma dispersão de 31,53\% em torno da média, enquanto que na Sul de Minas a variação ficou em 44,26\%, o que denota maior variação em torno da média nesta região.

A Tabela 2 apresenta os resultados da análise de sensibilidade, mostrando o efeito sobre a rentabilidade dos produtores de mamona nas regiões da Zona da Mata e Sul de Minas.

Observou-se que para o sistema de produção da Zona da Mata, o preço recebido e a produtividade, foram as variáveis que apresentaram maior impacto sobre o índice de eficiência. Assim, uma queda de $1 \%$ no preço recebido, provocaria uma redução na receita de $0,66 \%$. Caso a queda fosse na produtividade, a redução seria de $0,64 \%$. Verifica-se, portanto, que variações na rentabilidade dos produtores da Zona da Mata se dá tanto por oscilações no preço, quanto na produtividade. 
Tabela 2 - Análise de sensibilidade do índice de eficiência econômica da produção de mamona nas regiões da Zona da Mata e Sul de Minas, safra 2005/2006

\begin{tabular}{|c|c|c|c|c|}
\hline \multirow{2}{*}{ Variáveis } & \multicolumn{2}{|c|}{ Zona da Mata } & \multicolumn{2}{|c|}{ Sul de Minas } \\
\hline & Regressão & Correlação & Regressão & Correlação \\
\hline $\begin{array}{l}\text { Preço } \\
\end{array}$ & 0,662 & 0,676 & 0,473 & 0,467 \\
\hline Produtividade & 0,639 & 0,582 & 0,630 & 0,642 \\
\hline Mão de Obra & $-0,311$ & $-0,307$ & $-0,365$ & $-0,333$ \\
\hline Materiais & $-0,155$ & $-0,139$ & $-0,274$ & $-0,269$ \\
\hline Máquinas e Implementos & $-0,077$ & $-0,075$ & $-0,280$ & $-0,263$ \\
\hline Depreciação & $-0,015$ & $-0,023$ & $-0,082$ & $-0,071$ \\
\hline$R$-Squared & \multicolumn{2}{|c|}{$96,54 \%$} & \multicolumn{2}{|c|}{$91,74 \%$} \\
\hline
\end{tabular}

Fonte: Resultados da pesquisa

No sistema de produção do Sul de Minas, a produtividade foi a variável que apresentou maior efeito sobre o indicador de eficiência econômica. Assim, uma queda de 1\% na produtividade, provocaria, uma redução na receita $0,63 \%$. Caso a queda fosse no preço, a redução seria de $0,47 \%$ evidenciando, portanto, uma sensibilidade menor do índice a possíveis oscilações de preço. Portanto, variações no índice do sistema de produção no Sul de Minas se dá, principalmente, por oscilações na produtividade.

O preço e a produtividade têm, como esperado, correlações positivas com a eficiência do sistema de produção na da Zona da Mata. Já no Sul de Minas, a variável preço apresentou-se menos relevante pois a correlação mostrou-se positiva fraca (coeficiente menor que 0,5 ).

Quanto aos custos operacionais nas duas regiões, a mão-de-obra, foi a variável mais sensível. Por outro lado, houveram diferenças significativas entre as regiões para as variáveis máquinas/implementos e materiais. No Sul de Minas a sensibilidade a estas variáveis mostrou-se mais elevada, refletindo o maior nível tecnológico dos produtores desta região (foram mais intensivos na utilização de máquina/implementos e materiais como adubo e calcário). Ressalta-se, ainda, que o coeficiente de regressão apresentou um excelente nível de ajustamento, pois, 96,54\% (Zona da Mata) e 91,74 \% (Sul de Minas) das variações no indicador de eficiência, são explicadas por alterações nas variáveis preço, produtividade, mão-de-obra, materiais, máquinas/implementos e depreciação. O restante da variação, se deveu a outras variáveis que não participaram do modelo, são os chamados erros aleatórios.

Na Figura 2 são apresentadas as distribuições de probabilidade acumulada do índice de eficiência econômica dos sistemas de produção de mamona nas regiões. 
É possível verificar que na Zona da Mata, o coeficiente de eficiência econômica se iguala à unidade em $43,26 \%$ de probabilidade. Portanto, existe $56,74 \%$ de chance dos produtores obterem índices superiores a um. Verifica-se que o sistema de produção desta região apresentou probabilidade de apenas $5 \%$ de que o coeficiente seja superior a 1,74 .

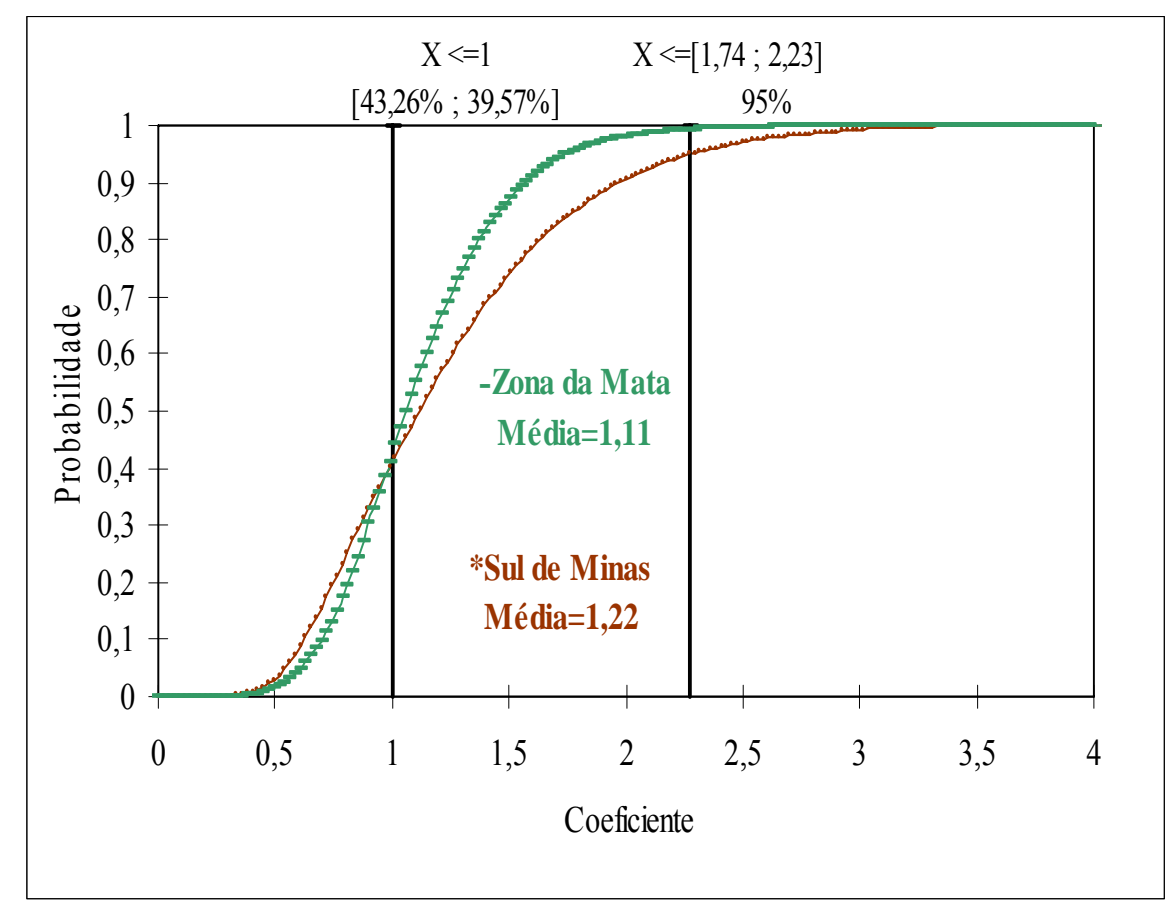

Figura 2 - Distribuição de probabilidade acumulada dos índices de eficiência econômica da produção de mamona nas regiões da Zona da Mata e Sul de Minas, safra 2005/2006

Fonte: Resultados da pesquisa

Observa-se que na região Sul de Minas, o coeficiente de eficiência econômica se iguala à unidade em $39,57 \%$ de probabilidade. Portanto, existem $60,43 \%$ de chances dos produtores obterem índices superiores a um. Verifica-se que o sistema de produção da região apresentou probabilidade de $95 \%$ de que o coeficiente seja menor ou igual a 2,23.

Verificou-se, também, que os índices de rentabilidade do sistema de produção do Sul de Minas passam a ser superiores aos do sistema da Zona da Mata a partir de 35\% de probabilidade acumulada de rentabilidade. Portanto, a relação Renda Bruta/Custos passa a ser favorável aos produtores da região Sul de Minas apenas quando se obtêm maiores níveis de produtividade por área, o que resulta em custo médio menor, já que os preços recebidos pelos produtores da mamona são iguais (Figura 2). 
Os custos de produção entre as regiões apresentaram uma diferença de 16,70 \% a mais no Sul de Minas, onde se gastou em média R\$ 895,23, para cultivar um hectare de mamona, enquanto na Zona da Mata ficou em R $\$ 767,10$. A diferença está na aplicação de calcário e no sulfato de amônia, materiais não consumidos na Zona da Mata.

No sistema de produção da mamona em Minas Gerais na safra 2005/2006, os produtores receberam um preço médio de $\mathrm{R} \$ 0,78 \mathrm{~kg}^{-1}$. Este valor cobriu os custos médios, estimado em $\mathrm{R} \$ 0,75 \mathrm{~kg}^{-1} \mathrm{e} \mathrm{R} \$$ $0,68 \mathrm{~kg}^{-1}$ para a Zona da Mata e Sul de Minas, respectivamente. Contudo, observa-se que os custos médios de produção nestas regiões estiveram em média $27,68 \%$ acima do preço mínimo, fixado pelo governo em $\mathrm{R} \$ 0,56 \mathrm{~kg}^{-1}$ para a safra. Contudo, o sistema apresentou probabilidade de eficiência baixa, pois os indicadores menores do que um apresentaram uma freqüência próximo a $50 \%$ de ocorrência, insuficiente para assegurar uma renda adequada para os produtores das regiões.

\subsubsection{Eficiência cultural}

No cálculo dos índices de Eficiências Cultural das regiões da Zona da Mata e Sul de Minas utilizou-se a distribuição de probabilidade triangular para as entradas totais, energia não renovável e as saídas energéticas, de acordo com a Tabela 3.

Tabela 3 - Entradas totais, energia fóssil e saídas de energia, em MJ.ha ${ }^{-1}$, no sistema de produção da mamona nas regiões da Zona da Mata e Sul de Minas, safra 2005/2006

\begin{tabular}{|c|c|c|c|c|c|c|}
\hline \multirow{2}{*}{ Indicadores } & \multicolumn{3}{|c|}{ Zona da Mata } & \multicolumn{3}{|c|}{ Sul de Minas } \\
\hline & Entradas & Energia & Saídas & Entradas & Energia & Saídas \\
\hline Máximo & 3511,81 & 2179,55 & 33252,05 & 6018,63 & 2394,79 & 49669,80 \\
\hline Mínimo & 3079,87 & 1789,59 & 20974,54 & 3250,84 & 941,34 & 25180,78 \\
\hline Média & 3287,12 & 1973,94 & 27559,98 & 4639,89 & 1615,36 & 37118,29 \\
\hline Mediana & 3283,68 & 1968,92 & 27735,51 & 4645,72 & 1592,08 & 36984,55 \\
\hline Moda & 3142,43 & 1921,09 & 23625,44 & 4079,11 & 1296,20 & 29028,08 \\
\hline Desvio padrão & 89,12 & 80,80 & 2561,14 & 562,14 & 299,55 & 5072,29 \\
\hline Iterações & \multicolumn{6}{|c|}{10000} \\
\hline Erros & \multicolumn{6}{|c|}{0} \\
\hline
\end{tabular}

Fonte: Resultados da pesquisa 
O sistema de produção da mamona apresentou uma saída energética média de 27.559,98 MJ.ha ${ }^{-1}$ na Zona da Mata. Na região Sul de Minas, gerou-se uma produção média de energia de 37.118,29 MJ.ha ${ }^{-1}$. A saída de energia nesta região é 34,68\% superior a da Zona da Mata.

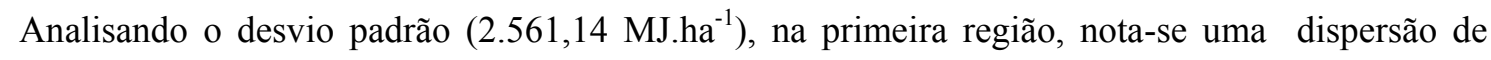
$9,29 \%$ da saída média de energia no sistema de produção. Na região Sul de Minas o desvio padrão de 5.072,29 MJ.ha ${ }^{-1}$, representou uma dispersão de 13,67\%. A diferença entre os desvios, mostra uma menor dispersão em torno da média na primeira região.

A partir da simulação demonstrada na Tabela 4, observa-se, nas duas regiões, que a média, mediana e moda apontam a probabilidade de ocorrência de coeficientes de eficiência energética maior do que um para a atividade de produção de mamona. Os valores máximos e mínimos do indicador de eficiência energética nas regiões também foram superiores à unidade.

Tabela 4 - Resultados estatísticos dos índices de eficiência cultural e eficiência energética no sistema de produção da mamona nas regiões da Zona da Mata e Sul de Minas, safra 2005/2006.

\begin{tabular}{l|c|c}
\hline Indicadores & Zona da Mata & Sul de Minas \\
\cline { 2 - 3 } & Eficiência Cultural & Eficiência Cultural \\
\hline Máximo & 10.75 & 14.75 \\
Mínimo & 6,09 & 4,48 \\
Média & 8,39 & 8,12 \\
Mediana & 8,44 & 7,99 \\
Moda & 8.27 & 7,65 \\
Desvio padrão & 0,81 & 1,53 \\
\hline Iteracões & \multicolumn{2}{c}{10000} \\
Erros
\end{tabular}

Fonte: Resultados da pesquisa

O desvio padrão do índice de eficiência cultural mostrou uma dispersão de $88,89 \%$ entre as regiões, 0,81 e 1,53 para a Zona da Mata e Sul de Minas, respectivamente. Quanto ao índice de eficiência energética, a dispersão também foi mais acentuada na região Sul de Minas com 5,63, do que na Zona da Mata com 1,53.

Do ponto de vista energético, o itinerário técnico do sistema estudado atingiu uma eficiência cultural média de 8,39 unidades energéticas na Zona da Mata e de 8,12 no Sul de Minas, ou seja, para cada unidade de energia aplicada no sistema, obteve-se mais de 8 unidades energéticas de retorno. Os valores máximos, medianos, moda e mínimos mostraram-se também altamente significativos. 
Na Figura 3, são apresentadas as distribuições de probabilidade acumulada do índice de eficiência cultural dos sistemas de produção de mamona nas regiões.

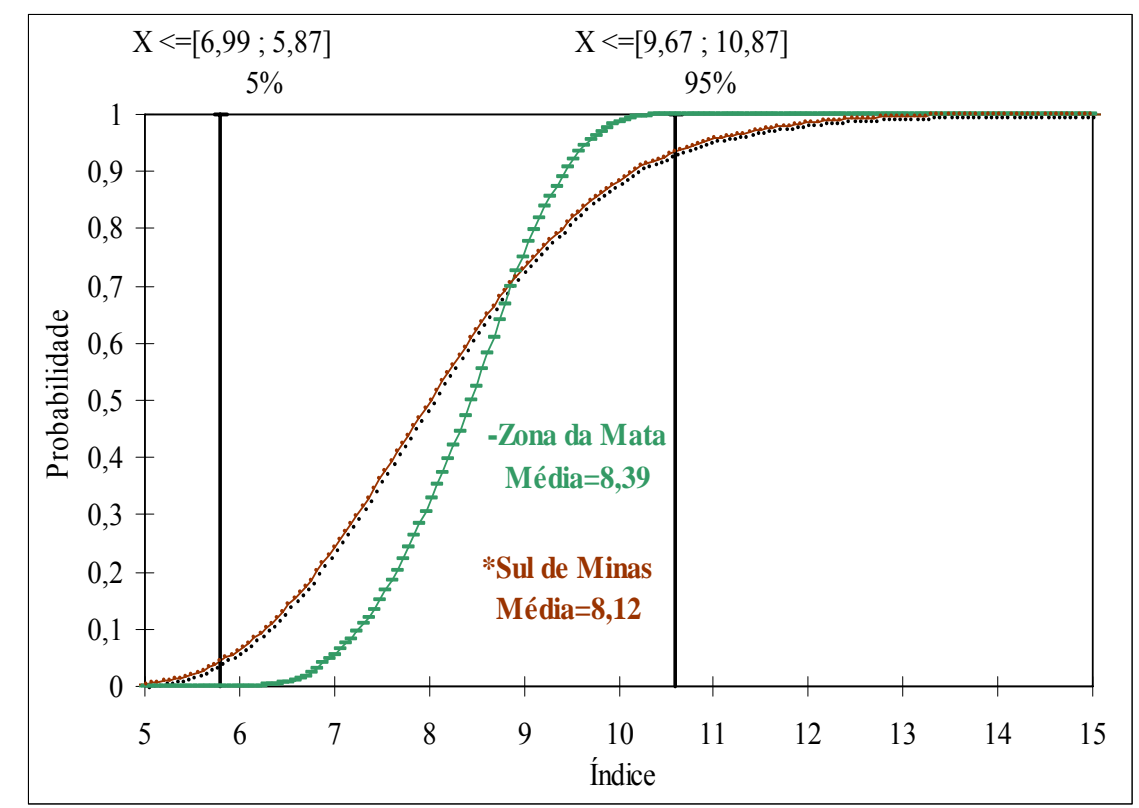

Figura 3 - Distribuição de probabilidade acumulada dos índices de eficiência cultural da produção de mamona nas regiões da Zona da Mata e Sul de Minas, safra 2005/2006

Fonte: Resultados da pesquisa

Observa-se que na Zona da Mata, a probabilidade do coeficiente de eficiência cultural ser menor ou igual a 6,99 unidades energéticas é de 5\% e que seja menor ou igual a 9,67 unidades energéticas é de $95 \%$. Verifica-se, portanto, que existe a probabilidade de $90 \%$ que o índice de eficiência cultural se encontre neste intervalo.

No que se refere à região Sul de Minas, o coeficiente de eficiência cultural, apresentou probabilidade e $5 \%$ de ser menor ou igual a 5,87 unidades energéticas e $95 \%$ que seja menor ou igual a 10,87 . Logo, existe a probabilidade de $90 \%$ que o índice de eficiência cultural da região se encontre neste intervalo.

Assim, os valores atingidos representam um sistema eficiente e sustentável energeticamente, pois, os indicadores obtidos de eficiência cultural e eficiência energética foram superiores a um. No entanto, a Zona da Mata apresentou uma eficiência cultura ligeiramente superior ao Sul de Minas. Enquanto esta alcançou uma maior eficiência energética. 


\section{CONCLUSÕES}

Com relação aos sistemas de produção da mamona em Minas Gerais na safra 2005/2006, constatou-se que as variáveis preço e produtividade foram as mais sensíveis para os produtores da Zona da Mata, enquanto que no Sul de Minas foi a produtividade.

O preço médio recebido cobriu os custos médios de produção, tanto na Zona da Mata, quanto no Sul de Minas. Contudo, observou-se que os custos nestas regiões estiveram bem acima do preço mínimo.

O sistema nas duas regiões de Minas Gerais mostrou probabilidade média de rentabilidade maior do que um acima de $58,59 \%$. Isto sugere que a produção de mamona nas regiões apresentaram probabilidade um pouco acima de $50 \%$ de resultado positivo, sendo portanto insuficiente para assegurar uma renda adequada para os produtores.

Nas regiões da Zona da Mata e Sul de Minas os balanços energéticos foram positivos. Ocorreu nas regiões eficiência cultural. Nessas regiões os sistemas mostraram-se também sustentáveis energeticamente, pois para cada unidade de energia não renovável que entrou nos sistemas obteve-se em média oito unidades energéticas adicionais de retorno.

Na região Zona da Mata, a energia proveniente de fonte fóssil com maior participação do óleo diesel de $61,52 \%$, predominou sobre a industrial e a biológica. Na região Sul de minas a grande participação dos fertilizantes de 53,23\%, foi a responsável pelo domínio da fonte industrial.

Em Minas Gerais, boa parte da energia biológica investida no processo produtivo é proveniente da força de trabalho dos membros da família.

Em suma, diante das constatações, a mamona não se mostrou capaz de apresentar uma rentabilidade adequada para os produtores, pois a renda gerada se deu em níveis de médio para alto risco em Minas Gerais. Os produtores de mamona geralmente possuem outras atividades geradoras de renda. Isso pode se tornar um problema para a competitividade da cadeia já que impede um maior comprometimento por parte do produtor. Para manter o produtor na atividade, a renda gerada com a produção da oleaginosa necessita ser maior e menos arriscada. Apesar da boa produtividade por hectare em Minas Gerias, média de $1.167 \mathrm{~kg} . \mathrm{ha}^{-1}$, quando comparadas com a média nacional, os desafios para alcançar sustentabilidade econômica desta alternativa energética permanece.

Nesse sentido, mesmo que do ponto de vista energético o resultado tenha sido favorável, sob a ótica da sustentabilidade econômica há necessidade de uma política de apoio à mamona, que contemple os problemas de instabilidade dos preços; de regulamentação para minimizar a falta de contratos; que forneça aos produtores assistência técnica, bem como cursos de treinamento e capacitação sobre os diversos aspectos do processo de produção. Não menos importantes são políticas que permitam mobilizar e organizar os 
produtores em associações e que estas funcionem como centros de referência e pontos de apoio, já que as expectativas dos produtores com o PNPB não se confirmaram.

\section{REFERÊNCIAS}

ABOISSA óleos vegetais. São Paulo, 2008. Disponível em: http://www.aboissa.com.br. Acesso em: 1 mar. 2008.

ALMEIDA, L. C. F. Avaliação energética econômica da cultura do milho em assentamento rural, Iperó-SP. 2007. 133 f. Tese (Doutorado em Agronomia/Energia na Agricultura)-Faculdade de Ciências Agronômicas, Universidade Estadual Paulista, Botucatu, 2007.

ASAE - AMERICAN SOCIETY OF AGRICULTURAL ENGINEERS. Agricultural machinery management data. In: ASAE standards 1999: standards engineering practices data. San Joseph, 1999. p. 359-66. (ASAE D497.4 JAN98).

BRASIL. Decreto n. 11.097, de 31 de janeiro de 2005. Diário Oficial da República Federativa do Brasil, Brasília, DF, p. 8, 14 jan. 2005. Poder Executivo. Seção 1.

BRASIL. Ministério de Minas e Energia. Diretrizes de política de agroenergia 2006-2011. Brasília, DF, 2005. Disponível em http://www.pdf4free.com/ Acesso: 12 jun. 2007.

. Balanço energético nacional. Brasília, DF, 2004. 168 p.

BUENO, O. C. Análise energética e eficiência do milho em assentamento rural, Itaberá-SP. 2002.146

p. Tese (Doutorado em Agronomia/Energia na Agricultura)-Faculdade de Ciências Agronômica, 
Universidade Estadual Paulista, Botucatu, 2002.

COHEN, L.; MANION, L. Research methods in education. 3 nd.London: Routledge, 1989. 266 p. FGV - FUNDAÇÃO GETULIO VARGAS.Rio de Janeiro, 2008. Preços agropecuários. Disponível em: $<$ http://www.fgvdados.fgv.br/>. Acesso em: 15 fev. 2008.

IBGE - INTITUTO BRASILEIRO DE GEOGRAFIA E ESTATÍSTICA. Produção agrícola municipal. Disponível em: $<$ http://www.ibge.gov.br>. Acesso: 20 maio 2008.

KORT-KAMP, M. et al, Estudo de CG/EM do óleo de sementes de mamona, proveniente de conversão a baixa temperatura In: REUNIÃO ANUAL DA SOCIEDADE BRASILEIRA DE QUÍMICA, 30, 2007, Águas de Lindóia. Anais... Águas de Lindóia: SBQ, 2007. 2 p.

MATSUNAGA, M. et al. A. Metodologia de custo de produção utilizado pelo IEA. Agricultura em São Paulo, São Paulo, v. 23, n. 1, p. 123-139, 1976.

PALISADE CORPORATION. @RISK 4.5 for industrial edition. New York, 2006. 450 p.

RISOUD, B. Développement durable et analyse énergétique d'exploitations agricoles. Économie Rurale, Lyon, n. 252, p. 16-27, juil/août, 1999.

ROMERO, M. G. C. Análise energética e econômica da cultura de algodão em sistemas agrícolas familiares. 2005. 139 f. Dissertação (Mestrado em Agronomia/Energia na Agricultura)-Faculdade de Ciências Agronômicas, Universidade Estadual Paulista, Botucatu, 2005.

SAVY FILHO, A. Mamona: tecnologia agrícola. Campinas, SP: EMOPI, 2005. 105 p. 